Article

\title{
Development of Molecular Distillation Based Simulation and Optimization of Refined Palm Oil Process Based on Response Surface Methodology
}

\author{
Noree Tehlah ${ }^{1}$, Pornsiri Kaewpradit ${ }^{1}$ and Iqbal M. Mujtaba ${ }^{2, *}$ \\ 1 Department of Chemical Engineering, Prince of Songkla University, Songkhla 90112, Thailand; \\ abie.ummie@gmail.com (N.T.); pornsiri.k@psu.ac.th (P.K.) \\ 2 Chemical Engineering Division, School of Engineering, University of Bradford, West Yorkshire BD7 1DP, UK \\ * Correspondence: i.m.mujtaba@bradford.ac.uk; Tel.: +44-1274-233-645
}

Received: 1 June 2017; Accepted: 3 July 2017; Published: 16 July 2017

\begin{abstract}
The deodorization of the refined palm oil process is simulated here using ASPEN HYSYS. In the absence of a library molecular distillation (MD) process in ASPEN HYSYS, first, a single flash vessel is considered to represent a falling film MD process which is simulated for a binary system taken from the literature and the model predictions are compared with the published work based on ASPEN PLUS and DISMOL. Second, the developed MD process is extended to simulate the deodorization process. Parameter estimation technique is used to estimate the Antoine's parameters based on literature data to calculate the pure component vapor pressure. The model predictions are then validated against the patented results of refining edible oil rich in natural carotenes and vitamin $\mathrm{E}$ and simulation results were found to be in good agreement, within a $\pm 2 \%$ error of the patented results. Third, Response Surface Methodology (RSM) is employed to develop non-linear second-order polynomial equations based model for the deodorization process and the effects of various operating parameters on the performance of the process are studied. Finally, an optimization framework is developed to maximize the concentration of beta-carotene, tocopherol and free fatty acid while optimizing the feed flow rate, temperature and pressure subject to process constrains. The optimum results of feed flow rate, temperature, and pressure were determined as $1291 \mathrm{~kg} / \mathrm{h}$, $147^{\circ} \mathrm{C}$ and $0.0007 \mathrm{kPa}$ respectively, and the concentration responses of beta- carotene, tocopherol and free fatty acid were found to be $0.000575,0.000937$ and 0.999840 respectively.
\end{abstract}

Keywords: process simulation; ASPEN HYSYS; molecular distillation; response surface methodology; optimization

\section{Introduction}

Palm oil is consumed worldwide. It is known that edible palm oil is full of nutrients that contribute to daily energy needs. The general compositions of crude palm oil are $95 \%$ of triglycerides, $3 \%-5 \%$ of fatty acid and $1 \%$ of minor trace component (phytonutrient). Palm oil is rich in phytonutrients; it provides a valuable source of beta-carotene and tocopherol (vitamin E). Crude palm oil has carotenes concentration of 1000 ppm-3000 ppm [1]. The carotenes from palm oil are a source of pro-vitamin $\mathrm{A}$ and recent findings have demonstrated that beta-carotene is used to inhibit tumor progression and hence, reduces cancer formation in humans. The purpose of the refined palm oil process is to remove unwanted fatty acid and impurities. It can be classified as both chemical and physical refining method. However, the physical method is proven to be more effective compared to the chemical method in terms of food safety and environment [2]. The physical method consists of three processes; degumming, bleaching and deodorization. The pre-process of deodorization involves operation at a temperature higher than $200{ }^{\circ} \mathrm{C}$ at normal pressure. It is performed to remove odor from the oil and 
additional fat. It generally results in not only removing fatty acid but also destroying all carotenes. Most of the carotenes in palm oil are destroyed in the conventional refining process to produce a lighter color oil [3].

The molecular distillation (MD) technique is a viable process to recover carotene from the palm oil and is suitable for such high a value-added product [4]. It is an important thermal separation technology. Typical application involves high boiling substances mainly of temperature-sensitive compounds. The compounds are distilled at a pressure range from 1 atmosphere to high vacuum [5]. At this pressure the evaporation temperature will fall during the short residence time, hence, no thermal decomposition can occur. Due to pressure being low as vacuum sometimes, it is known as a vacuum distillation column. Mean free path has an effect on this separation process. The mean free path of MD column is longer than the distance of evaporator and condenser. As a result, the molecules reach the condensing surface without being swerved on collision of others foreign gas. The larger molecule size has a shorter mean free path. Therefore, MD separates substances by its molecular weight. The main objectives of this research are divided into four sections: (a) MD process development and validation for a binary system from literature; (b) Application of the MD process for palm oil deodorization and validation of the process against patented experimental data; (c) Design of experiment by Response Surface Methodology (RSM) leading to the development of non-linear equations based MD model for palm oil deodorization; and (d) Optimization of the deodorization process based on the non-linear equations developed in (c). Note, there are many prevalent applications of RSM in food science, chemical and biological engineering related to molecular distillation [6-9].

Optimization in engineering shows an important methodology to enhance the process rather than making decisions intuitively. Many techniques and algorithms, such as neural network, genetic algorithm, Monte Carlo, Excel solver and others have been successfully applied in various processes. Here, Excel solver has been used for optimizing the operation of the refined palm oil process. The simulation, design of experiment and optimization are presented and discussed in later sections.

\section{Molecular Distillation Process: Modeling and Validation}

In this work, MD is used for the deodorization of palm oil. The objective of this section is to develop and simulate a molecular distillation process. Since there was no library model available in ASPEN HYSYS to simulate a falling film molecular distillation therefore, a simulation of single flash vessel was proposed to represent MD, as considered by other authors in previous studies [10]. In order to ensure that the simulation of MD in ASPEN HYSYS was valid, we referred to the study by the authors of [10] for the development of a computational tool for simulating MD process in oil refining using ASPEN PLUS and validation of the results against those predicted by DISMOL (a dedicated molecular distillation process simulator). In their study, an equi-molar mixture of Dibutyl phthalate (DBP) and Dibutyl sebacate (DBS) was fed to the flash process at pressure 0.133 Pa with an initial feed flow rate of $50 \mathrm{~kg} / \mathrm{h}$. Temperature was manipulated to achieve the same distillation mass ratio with DISMOL simulator (0.2120). Their ASPEN PLUS results are shown in Figures 1 and 2 together with the results of this work, which used ASPEN HYSYS with Redlich Kwong Soave with Wong Sandler mixture rules (RKSWS) for the calculation of thermo-physical properties. 


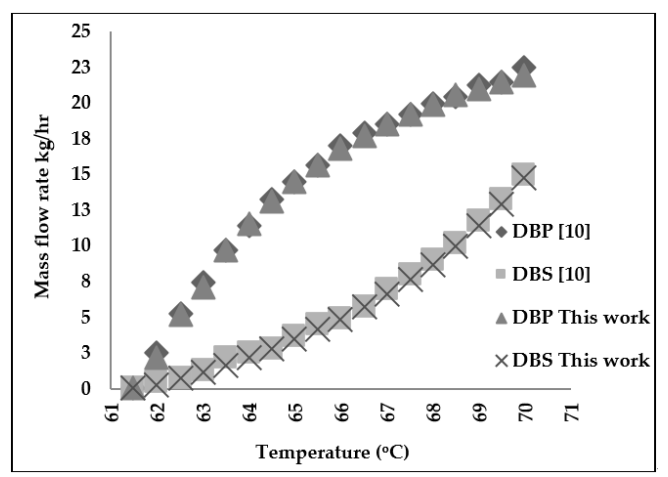

Figure 1. Comparison of distillated mass flow rate in study [10] and this work as a function of flash vessel operating temperature $\left({ }^{\circ} \mathrm{C}\right)$.

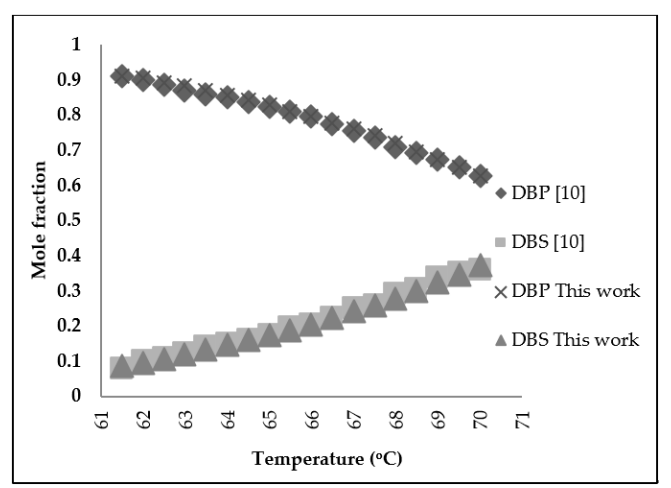

Figure 2. Comparison of distillate mole fraction in study [10] and this work as a function of flash vessel operating temperature $\left({ }^{\circ} \mathrm{C}\right)$.

The plotted data between ASPEN PLUS and ASPEN HYSYS seem to be in very good agreement. In order to achieve the same distillation mass ratio obtained by DISMOL, the flash equipment for ASPEN PLUS and ASPEN HYSYS had to operate at a temperature of $63.1^{\circ} \mathrm{C}$ and $63.5^{\circ} \mathrm{C}$ respectively. Both temperatures result in higher molar fraction of DBP in distillate and lower DBP at residue. Equation 1 was proposed by the authors of [10] to transform the flash result into MD. The efficiency factor is multiplied with the molar fraction for DBP at distillate and DBP molar fraction at residue before mass balance equations are solved.

$$
\begin{gathered}
\eta=\frac{T \text { flash }(K)}{T \operatorname{DISMOL}(K)} \\
\eta_{\text {ASPEN PLUS }}=\frac{336.26}{369}=0.91 \\
\eta_{\text {ASPEN HYSYS }}=\frac{336.66}{369}=0.91
\end{gathered}
$$

where $\eta$ is the efficiency factor.

The results are summarized in Table 1. It is clear that the predictions of ASPEN HYSYS are close to that of ASPEN PLUS in terms of temperature and close to DISMOL in terms of Residue DBP molar fraction. In terms of distillation of DBP molar fraction, both ASPEN PLUS and ASPEN HYSYS predictions are within $\pm 2 \%$ of that predicted by DISMOL. Thus, the developed flash process within ASPEN HYSYS can be applied to any MD process, such as the palm oil deodorization process considered in this work. 
Table 1. Results of the DISMOL simulator, ASPEN PLUS and that developed in ASPEN HYSYS.

\begin{tabular}{cccc}
\hline Parameters & DIMSOL & ASPEN PLUS [10] & ASPEN HYSYS (This Work) \\
\hline Operating temperature (K) & 369 & 336 & 336 \\
Distillation mass ratio & 0.212 & 0.212 & 0.212 \\
Distillation DBP molar fraction & 0.775 & 0.790 & 0.793 \\
Residue DBP molar fraction & 0.429 & 0.409 & 0.420 \\
\hline
\end{tabular}

\section{Refined Palm Oil Deodorization Process Simulation by ASPEN HYSYS}

The MD process model developed and validated in Section 2 is now used for the simulation of the deodorization of refined palm oil process in ASPEN HYSYS. Figure 3 shows the MD process for deodorization in refined palm oil. The operation is carried out at a high vacuum pressure between $5 \times 10^{-4}$ and $8 \times 10^{-4} \mathrm{kPa}$, at a temperature of $175{ }^{\circ} \mathrm{C}-180{ }^{\circ} \mathrm{C}$ and a feed flow rate between 250 and $2000 \mathrm{~kg} / \mathrm{h} \mathrm{[11]}$. The vapor pressure estimations and the simulation of refined palm oil are discussed below.

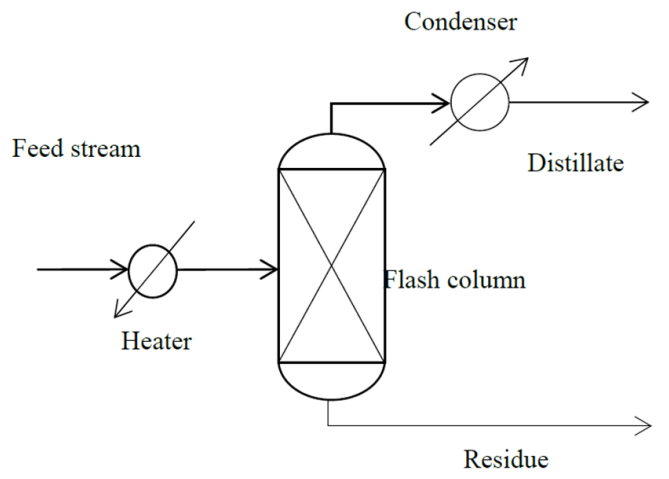

Figure 3. Refined palm oil deodorization process.

\subsection{Vapor Pressure Estimation}

To design and simulate a molecular distillation, thermo-physical properties, vapor pressure of each component and the thermodynamic model are all required. This process used Redlich Kwong ASPEN (RK-Aspen) as a thermodynamic model or property method to calculate physical properties. The RK-Aspen is an equation of state model (EOS) that is good for vapor phase modeling with fewer binary parameters required and is consistent in critical region [12].

The feed stream of the process consists of five main components: tripalmitin triolein, oleic acid, tocopherol and beta-carotene. The mass fraction of each component is shown in Table 2. For a multicomponent system, it was not an easy task to calculate molar fraction by use of mass and component balances in an underdetermined situation. Consequently, thermodynamic properties and vapor pressure or pure component parameters for Antoine equations are required, and must be established.

Table 2. Composition of refined palm oil and its properties.

\begin{tabular}{ccccc}
\hline Components & Mass Fraction & MW & Formula & CAS No. \\
\hline Tripalmitin & 0.493682 & 807.320 & $\mathrm{C}_{51} \mathrm{H}_{98} \mathrm{O}_{6}$ & $555-44-2$ \\
Triolein & 0.470891 & 885.449 & $\mathrm{C}_{57} \mathrm{H}_{104} \mathrm{O}_{6}$ & $122-32-7$ \\
Oleic acid & 0.033899 & 282.467 & $\mathrm{C}_{18} \mathrm{H}_{34} \mathrm{O}_{2}$ & $112-80-1$ \\
Tocopherol & 0.000886 & 430.706 & $\mathrm{C}_{29} \mathrm{H}_{50} \mathrm{O}_{2}$ & $59-02-9$ \\
Beta-carotene & 0.000552 & 536.873 & $\mathrm{C}_{40} \mathrm{H}_{56}$ & $7235-40-7$ \\
\hline
\end{tabular}


The thermo-physical properties are introduced in the simulation in terms of physical properties such as boiling point $\left(T_{B}\right)$, critical temperature $\left(T_{C}\right)$, critical pressure $\left(P_{C}\right)$, acentric factor $(\omega)$ and liquid molar volume $\left(V_{120}\right)$ for each component, and can be seen in Table A1 in the Appendix, as accomplished by Lim et al. [13]. Equation (2) refers to an extension of the Antoine equation from Lim et al.'s work, and its parameters are shown in Table 3. However, the equation available in ASPEN HYSYS is shown in Equation (3). Therefore, the parameters of the Antoine equation used in this study were obtained by minimizing the least square error of Equation (4) through Solver Add-in, in Microsoft Excel and Matlab optimization.

$$
\begin{gathered}
\ln P^{\text {calc }}=A_{1}-B_{1} / T+C_{1} T+D_{1} \cdot \ln T+E_{1} T^{6} \\
\ln P^{\text {exp }}=A_{2}+B_{2} /\left(T+C_{2}\right)+D_{2} \cdot \ln T+E_{2} T^{6}
\end{gathered}
$$

where $A, B, C, D$ and $E$ are the Antoine Parameters. $P$ is the vapor pressure in $\mathrm{kPa}$, and $T$ is temperature in $\mathrm{K}$.

$$
S=\sum_{i=1}^{m}\left[\ln P_{i}^{\text {calc }}-\ln P_{i}^{\text {exp }}\right]^{2}
$$

where $S$ is sum of the squared error, $m$ is the number of experimental data point within the temperature range of $373 \mathrm{~K}-503 \mathrm{~K}, P_{i}^{\text {calc }}$ is the calculated vapour pressure obtained from Lim et al.'s work [13] using Equation (2) and $P_{i}^{\exp }$ is the expected vapour pressure in Equation (3) (as available in ASPEN HYSYS). The pure component parameters for modified Antoine equation (Equation (3)) and coefficient of determination $\left(R^{2}\right)$ of each component are summarized in Table 4 . The coefficient of determination was calculated by regression data analysis in Microsoft Excel between the correlation of $\ln P^{\text {calc }}$ and $\ln P^{\exp }$ as Equation (5).

$$
R^{2}=\frac{\text { Regression sum of square }}{\text { Total sum of square }}=\frac{\sum_{i=1}^{m}\left[\ln \hat{P}_{i}^{\exp }-\ln \bar{P}_{i}^{\exp }\right]^{2}}{\sum_{i=1}^{m}\left[\ln P_{i}^{\exp }-\ln \bar{P}_{i}^{\exp }\right]^{2}}
$$

where $\ln P_{i}^{\text {exp }}, \ln \bar{P}_{i}^{\text {exp }}$ and $\ln \hat{P}_{i}^{\text {exp }}$ are the observed values of the dependent variable, mean or average and fitted values, respectively.

Table 3. Pure component parameters for Equation (2), reproduced with permission from [13]. Copyright Springer, 2003.

\begin{tabular}{cccccc}
\hline \multirow{2}{*}{ Component } & \multicolumn{5}{c}{ Antoine Parameters } \\
\cline { 2 - 6 } & $\boldsymbol{A}_{\mathbf{1}}$ & $\boldsymbol{B}_{\mathbf{1}}$ & $\boldsymbol{C}_{\mathbf{1}}$ & $\boldsymbol{D}_{\mathbf{1}}$ & $\boldsymbol{E}_{\mathbf{1}}$ \\
\hline Tripalmitin & 108,841 & $-4,098,952$ & 19.96 & $-17,792$ & $-3.6 \times 10^{-15}$ \\
Triolein & $-514,215$ & $19,737,838$ & -91.13 & 83,685 & $1.4 \times 10^{-15}$ \\
Oleic acid & 136.45 & $-19,702$ & -0.01 & -14.87 & $7.2 \times 10^{-19}$ \\
Tocopherol & -15.90 & -5118 & 0.05 & 0 & 0.00 \\
$\beta$-carotene & -91.32 & -15.90 & 0.239 & 0 & 0.00 \\
\hline
\end{tabular}

Table 4. Estimated pure component parameters for modified Antoine equation (Equation (3)).

\begin{tabular}{ccccccc}
\hline \multirow{2}{*}{ Component } & \multicolumn{5}{c}{ Antoine Parameters } & \multirow{2}{*}{$\boldsymbol{R}^{\mathbf{2}}$} \\
\cline { 2 - 6 } & $\boldsymbol{A}_{\mathbf{2}}$ & $\boldsymbol{B}_{\mathbf{2}}$ & $\boldsymbol{C}_{\mathbf{2}}$ & $\boldsymbol{D}_{\mathbf{2}}$ & $\boldsymbol{E}_{\mathbf{2}}$ & \\
\hline Tripalmitin & $1.509 \times 10^{5}$ & $1.196 \times 10^{5}$ & $-0.074 \times 10^{5}$ & $-0.21 \times 10^{5}$ & 0.00 & 0.99 \\
Triolein & $-0.013 \times 10^{7}$ & $-3.170 \times 10^{7}$ & 0.000 & 0.000 & 0.00 & 0.99 \\
Oleic acid & 519.688 & -0.106 & -399.010 & -71.37 & 0.00 & 0.99 \\
Tocopherol & -64.849 & 594.994 & -219.253 & 13.052 & 0.00 & 0.99 \\
$\beta$-carotene & 24.079 & $-16,160$ & -100.623 & 5.191 & 0.00 & 0.99 \\
\hline
\end{tabular}




\subsection{Refined Palm Oil Deodorization Process Simulation and Validation}

The main task of this part is to simulate, validate, and compare the performance of molecular distillation with 4 experiments reported in the patent of refining of edible oil rich in natural carotene and vitamin E [11]. The distillation mass ratio for the process was 0.036 . The MD process was simulated, and prediction error of the simulations is shown in Table 5.

Table 5. Simulations results of refining of edible oil in study [11] and this work.

\begin{tabular}{lcccccc}
\hline \multirow{2}{*}{ Condition } & \multirow{2}{*}{ Distillation Mass Ratio } & \multicolumn{2}{c}{ Patent Recovery } & \multicolumn{2}{c}{ Simulation Recovery } & \multicolumn{2}{c}{ Prediction Error } \\
\cline { 3 - 7 } & & $\mathbf{k g} / \mathbf{h}$ & Percent (\%) & $\mathbf{k g} / \mathbf{h}$ & Percent (\%) & $\mathbf{( \% )}$ \\
\hline Simulation 1 & 0.036 & 1.0395 & $95.98 \%$ & 1.0351 & $98.96 \%$ & $3.1 \%$ \\
Simulation 2 & 0.036 & 0.5449 & $98.73 \%$ & 0.5467 & $99.03 \%$ & $0.3 \%$ \\
Simulation 3 & 0.036 & 0.1249 & $98.03 \%$ & 0.1266 & $99.29 \%$ & $1.218 \%$ \\
Simulation 4 & 0.036 & 0.2969 & $97.38 \%$ & 0.3258 & $99.25 \%$ & $1.87 \%$ \\
\hline
\end{tabular}

The carotene recovery of the patent recorded in [11] and the current work is demonstrated in Figure 4. It can be clearly seen that the refined palm oil deodorization process simulation results show a very good agreement with the patent, with a prediction error of less than $3 \%$.

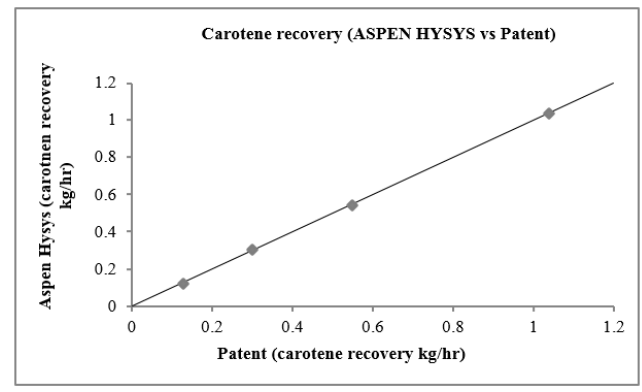

Figure 4. Carotene recovery of refining of edible oil in study [11] and this work.

\section{RSM-Based Process Model}

While we could use the ASPEN HYSYS based process model developed in Section 3 for further simulation and optimisation, here, we have decided to develop a Response Surface Methodology (RSM)-based process model and we resort to Design of Experiments (DoE). Like many authors [14,15] who have considered process simulator as an alternative to real process experiments and applied RSM on the simulated data in the past, we assume the ASPEN HYSYS based MD process described in Section 3 as the real process for the deodorization of refined palm oil.

The design of experiment (DoE) consists of three stages which are (i) screening methodology (preliminary research) to identify the vital factors, (ii) response surface methodology and (iii) model validation. The screening method is to detect factors that impact the process. In preliminary research for molecular distillation [6-9], it is found that temperatures at feed container, temperature at condenser and rotation speed of the design are the factors that had effects on the concentration of beta-carotene, tocopherol and free fatty acid. Therefore, these parameters are kept constant. Both temperatures at feed container and at condenser are fixed at $150^{\circ} \mathrm{C}$. In this work, the feed flow rate, column pressure and column temperature are manipulated for further investigation of the process.

RSM with Central Composite Design (CCD) is applied to develop, and obtain a quadratic model. The CCD consists of three portions which are the fraction of $2^{\mathrm{k}}$ factorial design (level are coded as 1 and $-1), 2 \mathrm{k}$ axial portion and the number of center point. In this case, the least number of 3 center points is used. Therefore, the design contained a total of 17 simulation runs according to Equation (6) [16]:

$$
N=2^{k}+2 k+n_{0}
$$


where $N$ is the number total runs, $k$ is independent variable, $n_{0}$ is number of center points.

The feed flow rate $\left(x_{1}\right)$, distillation temperature $\left(x_{2}\right)$, and pressure $\left(x_{3}\right)$ were independent variables. These three variables are used and assumed to influence the responses of beta-carotene concentration $\left(y_{1}\right)$, tocopherol concentration $\left(y_{2}\right)$ at residue stream and free fatty acid (oleic acid) concentration $\left(y_{3}\right)$ in the distillate stream.

In CCD, the axial value is set as 0.59 . High value and low value are coded as 1 and -1 respectively while 0 was the center point code [17]. The coded values and its design range are shown in Tables 6 and 7 respectively. Those values are coded according to the following Equations (7)-(9) [17].

$$
\begin{gathered}
X_{1}=\frac{x_{1}-\overline{x_{1}}}{0.5\left(x_{1 H}-x_{1 L}\right)}=\frac{x_{1}-1500}{500} \\
X_{2}=\frac{x_{2}-\overline{x_{2}}}{0.5\left(x_{2 H}-x_{2 L}\right)}=\frac{x_{2}-150}{50} \\
X_{3}=\frac{x_{3}-\overline{x_{3}}}{0.5\left(x_{3 H}-x_{3 L}\right)}=\frac{x_{3}-5.05 \times 10^{-4}}{4.95 \times 10^{-4}}
\end{gathered}
$$

where $X_{i}$ and $x_{\mathrm{i}}$ are coded and actual values of variable $i$, respectively; and subscript $i$ are $1=$ feed flow rate, 2 = column temperature and $3=$ column pressure, and $H, L$ are highest and lowest values.

Table 6. Central composite circumscribed (Min and Max = Star Points) design with three independent variables.

\begin{tabular}{|c|c|c|c|c|c|}
\hline Variables & & Coded Var & bles and Design & Zange & \\
\hline Feed flow rate $(\mathrm{kg} / \mathrm{h})$ & $1000(-1)$ & $1203(-0.59)$ & $1500(0)$ & $1797(0.59)$ & $2000(1)$ \\
\hline Temperature $\left({ }^{\circ} \mathrm{C}\right)$ & $100(-1)$ & $120(-0.59)$ & $150(0)$ & $180(0.59)$ & $200(1)$ \\
\hline Pressure $(\mathrm{kPa})$ & $1.00 \times 10^{-5}(-1)$ & $2.11 \times 10^{-4}(-0.59)$ & $5.05 \times 10^{-4}(0)$ & $7.99 \times 10^{-4}(0.59)$ & $1.00 \times 10^{-3}(1)$ \\
\hline
\end{tabular}

\begin{tabular}{cccc}
\hline \multicolumn{4}{c}{ Coded Variables } \\
\hline Run & $\boldsymbol{X}_{\mathbf{1}}$ & $\boldsymbol{X}_{\mathbf{2}}$ & $\boldsymbol{X}_{\mathbf{3}}$ \\
\hline 1 & 0 & 0 & -1 \\
2 & 0 & 0 & 0 \\
3 & -1 & 0 & 0 \\
4 & 0 & 0 & 0 \\
5 & 0 & 1 & 0 \\
6 & -0.59 & 0.59 & -0.59 \\
7 & 0 & 0 & 0 \\
8 & 0.59 & -0.59 & 0.59 \\
9 & -0.59 & -0.59 & -0.59 \\
10 & 0.59 & 0.59 & 0.59 \\
11 & 0 & -1 & 0 \\
12 & 0.59 & 0.59 & -0.59 \\
13 & -0.59 & 0.59 & 0.59 \\
14 & 0.59 & -0.59 & -0.59 \\
15 & 0 & 0 & 1 \\
16 & 1 & 0 & 0 \\
17 & -0.59 & -0.59 & 0.59 \\
\hline
\end{tabular}

Table 7. Coded variables and design range.

The regression analysis of the responses is fitted with non-linear second-order polynomial equation represented by Equation (10):

$$
y=\beta_{0}+\sum_{i=1}^{3} \beta_{i} x_{i}+\sum_{i=1}^{3} \beta_{i i} x_{i}^{2}+\sum_{i=1}^{3} \sum_{j=1}^{3} \beta_{i j} x_{i} x_{j}
$$


where $y$ is the responses, $\beta_{0}$ is constant number, $\beta_{i}, \beta_{i i}$ and $\beta_{i j}$ are coefficients for the linear, quadratic and interaction, respectively.

Table 8 shows the experimental (simulated by MD process described in Section 3) results for 17 runs of independent variables with respect to responses: $\left(y_{1}\right),\left(y_{2}\right)$ and $\left(y_{3}\right)$. The regression coefficient value for linear, quadratic and interaction are shown in Table 9.

Table 8. Experimental design using Central Composite Design (CCD) of 17 runs.

\begin{tabular}{|c|c|c|c|c|c|c|}
\hline \multirow{2}{*}{ Run } & \multicolumn{3}{|c|}{ Input Variables } & \multicolumn{3}{|c|}{ Composition Mass Fraction (Responses) } \\
\hline & $x_{1}(\mathrm{~kg} / \mathrm{h})$ & $x_{2}\left({ }^{\circ} \mathrm{C}\right)$ & $x_{3}\left(10^{-4} \mathrm{kPa}\right)$ & $y_{1}\left(10^{-4}\right)$ & $y_{2}\left(10^{-4}\right)$ & $y_{3}$ \\
\hline 1 & 1500 & 150 & 0.10 & 0.28 & 0.54 & 0.09 \\
\hline 2 & 1500 & 150 & 5.05 & 5.27 & 8.62 & 0.91 \\
\hline 3 & 1000 & 150 & 5.05 & 5.27 & 8.62 & 0.91 \\
\hline 4 & 1500 & 150 & 5.05 & 5.27 & 8.62 & 0.91 \\
\hline 5 & 1500 & 200 & 5.05 & 7.27 & 9.63 & 0.08 \\
\hline 6 & 1203 & 180 & 2.11 & 1.13 & 1.73 & 0.12 \\
\hline 7 & 1500 & 150 & 5.05 & 5.27 & 8.62 & 0.91 \\
\hline 8 & 1797 & 120 & 7.99 & 5.64 & 9.07 & 1.00 \\
\hline 9 & 1203 & 120 & 2.11 & 5.57 & 9.04 & 0.99 \\
\hline 10 & 1797 & 180 & 7.99 & 4.07 & 6.45 & 0.48 \\
\hline 11 & 1500 & 100 & 5.05 & 5.57 & 8.95 & 1.00 \\
\hline 12 & 1797 & 180 & 2.11 & 1.13 & 1.73 & 0.12 \\
\hline 13 & 1203 & 180 & 7.99 & 4.07 & 6.45 & 0.48 \\
\hline 14 & 1797 & 120 & 2.11 & 5.57 & 9.04 & 0.99 \\
\hline 15 & 1500 & 150 & 1.00 & 5.48 & 8.89 & 0.96 \\
\hline 16 & 2000 & 150 & 5.05 & 5.27 & 8.62 & 0.91 \\
\hline 17 & 1203 & 120 & 7.99 & 5.64 & 9.07 & 1.00 \\
\hline
\end{tabular}

The effect of each independent variable on the responses according to 17 runs is described below.

Table 9. Estimated regression coefficient for refined palm oil.

\begin{tabular}{cccc}
\hline Term & Coefficient & Coefficient & Coefficient \\
\hline Constant & $5.25 \times 10^{-4}$ & $8.60 \times 10^{-4}$ & $9.15 \times 10^{-1}$ \\
$x_{1}$ & $1.35 \times 10^{-20}$ & $3.49 \times 10^{-20}$ & $-1.27 \times 10^{-18}$ \\
$x_{2}$ & $-2.49 \times 10^{-4}$ & $-4.12 \times 10^{-4}$ & $-5.34 \times 10^{-1}$ \\
$x_{3}$ & $1.83 \times 10^{-4}$ & $2.92 \times 10^{-4}$ & $2.69 \times 10^{-1}$ \\
$x_{1} x_{1}$ & $2.42 \times 10^{-5}$ & $3.54 \times 10^{-5}$ & $-1.63 \times 10^{-3}$ \\
$x_{2} x_{2}$ & $-1.88 \times 10^{-4}$ & $-3.31 \times 10^{-4}$ & $-3.74 \times 10^{-1}$ \\
$x_{3} x_{3}$ & $-2.15 \times 10^{-4}$ & $-3.56 \times 10^{-4}$ & $-3.91 \times 10^{-1}$ \\
$x_{1} x_{2}$ & $6.88 \times 10^{-21}$ & $-1.38 \times 10^{-20}$ & $2.82 \times 10^{-17}$ \\
$x_{1} x_{3}$ & $-1.38 \times 10^{-20}$ & $9.01 \times 10^{-21}$ & $2.73 \times 10^{-17}$ \\
$x_{2} x_{3}$ & $2.07 \times 10^{-4}$ & $3.38 \times 10^{-4}$ & $2.50 \times 10^{-1}$ \\
\hline
\end{tabular}

\subsection{The Effect of Feed Flow Rate on Responses}

The results of feed flow rate on the responses of beta-carotene $\left(y_{1}\right)$, tocopherol $\left(y_{2}\right)$ and FFA $\left(y_{3}\right)$ are investigated at a temperature of $150{ }^{\circ} \mathrm{C}$ and pressure of $5.05 \times 10^{-4} \mathrm{kPa}$ (run No. 2 and 3). Decreasing the feed flow rate from 1500 to $1000 \mathrm{~kg} / \mathrm{h}$ at constant temperature and pressure does not make any changes to the responses. The contour plots and response surface curves in Figures 5-7, reveal that the feed flow rate does not show significant deviation on responses. 


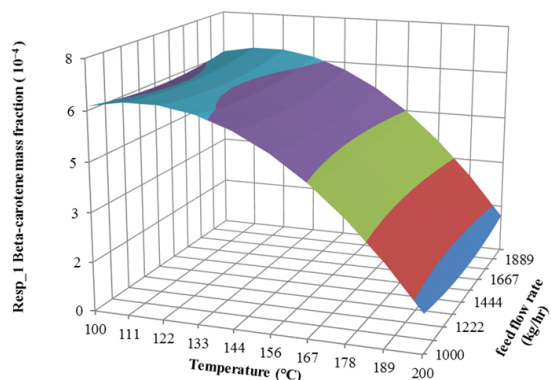

(a)
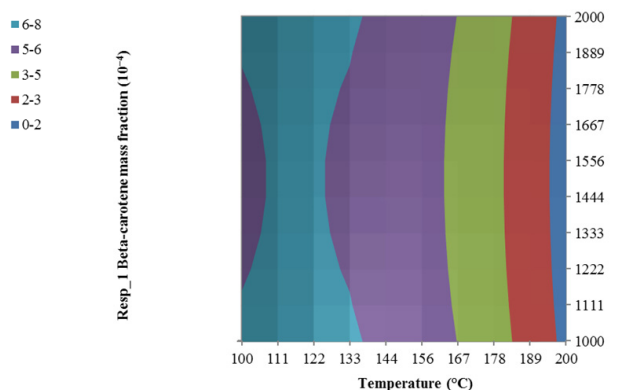

(b)

Figure 5. Response surface curve (a) and contour plot (b) of beta-carotene concentration as a function of temperature and feed flow rate.

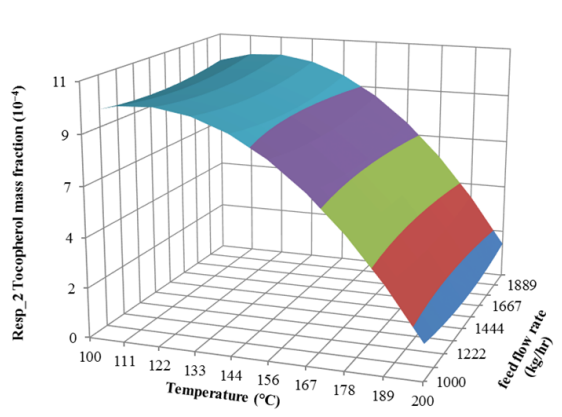

(a)

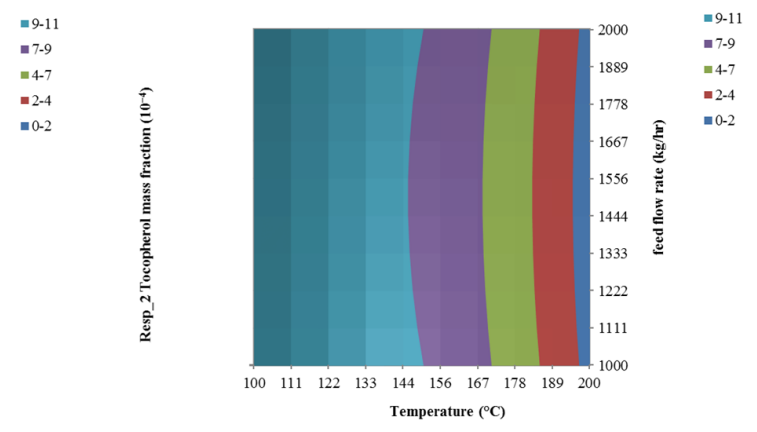

(b)

Figure 6. Response surface curve (a) and contour plot (b) of tocopherol concentration as a function of temperature and feed flow.

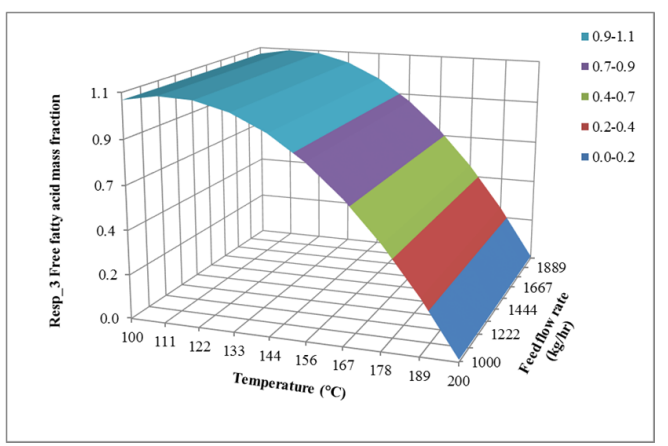

(a)

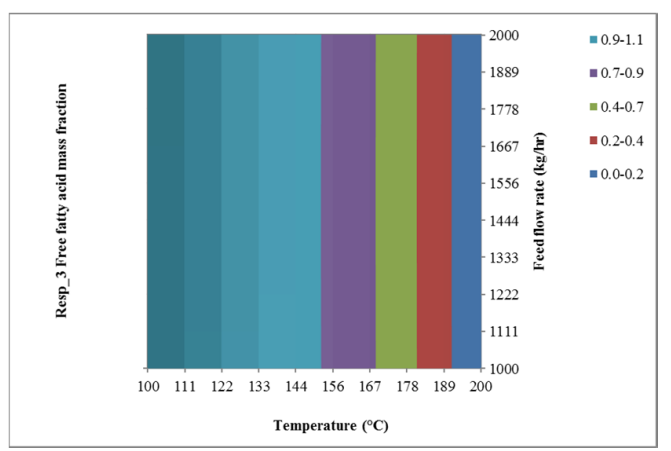

(b)

Figure 7. Response surface curve (a) and contour plot (b) of FFA concentration as a function of temperature and feed flow.

\subsection{The Effect of Temperature on Responses}

Concentration of beta-carotene, tocopherol and FFA as a function of temperature are investigated at constant feed flow rate and pressure at $1500 \mathrm{~kg} / \mathrm{h}$ and $5.05 \times 10^{-4} \mathrm{kPa}$ respectively (run no. 4 and 5). In Figures 8-10, the temperature shows significant deviation in the responses of beta-carotene $\left(y_{1}\right)$, tocopherol $\left(y_{2}\right)$ and FFA $\left(y_{3}\right)$. It can be clearly seen that, the concentrations of the responses decrease with increasing the distilling temperature. According to the Clauses Clapeyron relation, the vapor pressure of substance increases non-linearly with temperature. Therefore, increasing temperature (Equation (11)) will increase mean free path which will lengthen the average distance of traveling molecule reaching the condensation board. The longer the distance of molecule travels the higher the 
rate of vaporization of molecule. As a result, low concentration of beta-carotene and tocopherol are found in the residue and low concentration of free fatty acid is found in the distillate.

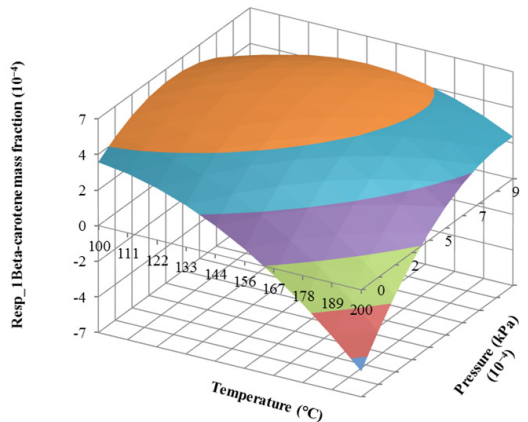

(a)

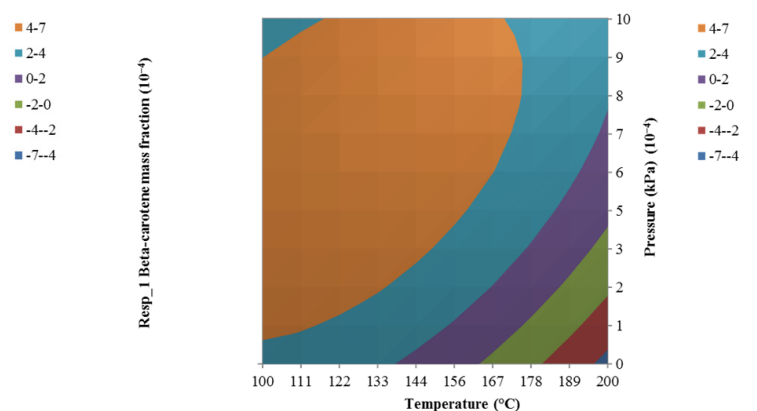

(b)

Figure 8. Response surface curve (a) and contour plots (b) of beta-carotene concentration as a function of temperature and pressure.

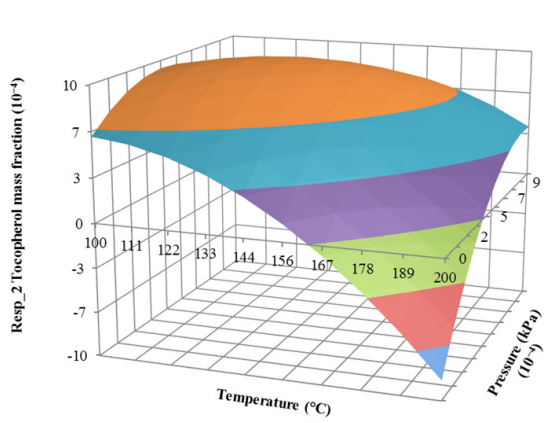

(a)
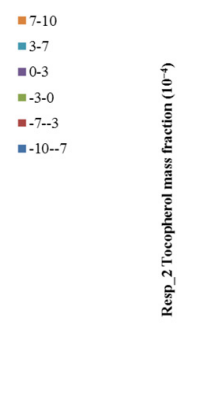

Figure 9. Response surface curve (a) and contour plot (b) of tocopherol concentration as a function of temperature and pressure.

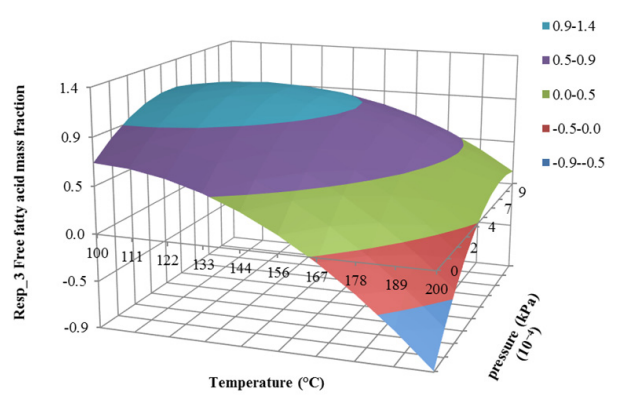

(a)

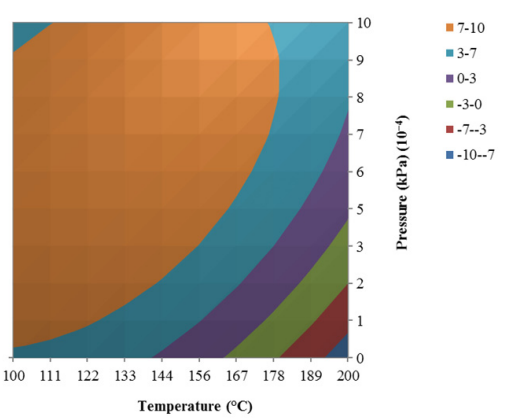

(b) 
condensation board. The shorter the average distance of traveling molecule the lesser the vaporization of molecule. Consequently, high concentration of beta-carotene and tocopherol are achieved at residue stream which consequently increase the free fatty acid concentration at the distillate.

$$
\lambda=\frac{R T}{\sqrt{2} \pi d^{2} N_{A} P}
$$

where $\lambda$ is the mean free path, $R$ is gas constant, $d$ is molecular diameter $N_{A}$ is Avogadro's number and $P$ is the pressure.

The independent variables and responses are fitted by the following second order polynomial Equations (12)-(14) which show complex relationships between the independent variables and the responses. In addition, term constants of $x_{1}, x_{1} x_{2}$, and $x_{1} x_{3}$ are not considered in this case due to the insignificant effect to the responses.

$$
\begin{aligned}
& y_{1}=5.25 \times 10^{-4}-2.49 \times 10^{-4} x_{2}+1.83 \times 10^{-4} x_{3}+2.42 \times 10^{-5} x_{1}{ }^{2}-1.88 \times 10^{-4} x_{2}{ }^{2}-2.15 \times 10^{-4} x_{3}{ }^{2}+2.07 \times 10^{-4} x_{2} x_{3} \\
& y_{2}=8.60 \times 10^{-4}-4.12 \times 10^{-4} x_{2}+2.92 \times 10^{-4} x_{3}+3.54 \times 10^{-5} x_{1}{ }^{2}-3.31 \times 10^{-4} x_{2}{ }^{2}-3.56 \times 10^{-4} x_{3}{ }^{2}+3.38 \times 10^{-4} x_{2} x_{3} \\
& y_{3}=9.15 \times 10^{-1}-5.34 \times 10^{-1} x_{2}+2.69 \times 10^{-1} x_{3}-1.63 \times 10^{-3} x_{1}{ }^{2}-3.74 \times 10^{-1} x_{2}{ }^{2}-3.91 \times 10^{-1} x_{3}{ }^{2}+2.50 \times 10^{-1} x_{2} x_{3}
\end{aligned}
$$

The $R^{2}$ value of responses, concentration of beta-carotene, tocopherol and FFA are $0.959,0.961$ and 0.951 respectively, show a very good fit. The nonlinear Equations (12)-(14) now represent the MD process model which will be used for optimizing the process in the next section.

It is observed that the response surface curves of beta-carotene, tocopherol and FFA concentration display a similar relationship with respect to independent variables. The concavity of the curves shows the optimum point of each of the responses. However, those concavities are not high enough to indicate the visually maximum point of responses.

\section{Optimization of MD for Refined Palm Oil Process}

In this section the aim is to find the optimum operating parameters that will maximize the concentration of beta-carotene, tocopherol at the residue and concentration of FFA at the distillate stream. The mathematical model (Equations (12)-(14)) and the objective function have been written in Equation (15). This work is more concerned with the enhancement of concentration of beta-carotene and tocopherol as $70 \%$, than it is with reducing the concentration of free fatty acid. Therefore, in the objective function, different weighting was applied by a factor of 0.7 in $y_{1}, y_{2}$ and 0.3 for $y_{3}$. The optimization variables are feed flow rate, temperature and pressure. Lower and upper bounds for variables are specified between a valid lower and upper bound. The actual (re-scaled) upper bound and lower bound is shown in the Table 10.

$$
\text { Maximize: } f(x)=0.7\left(y_{1}+y_{2}\right)+0.3 y_{3}
$$

Table 10. Upper bound and lower bound for independent variables.

\begin{tabular}{ccc}
\hline Variable Description & Low Bound & High Bound \\
\hline Inlet Mass flow rate $(\mathrm{kg} / \mathrm{h})$ & 1000 & 2000 \\
Temperature $\left({ }^{\circ} \mathrm{C}\right)$ & 100 & 200 \\
Pressure $(\mathrm{kPa})$ & 0.001 & 0.00001 \\
\hline
\end{tabular}

Subject to: $h(x)=1000 \leq x_{1} \leq 2000,100 \leq x_{2} \leq 200,0.00001 \leq x_{3} \leq 0.001,0 \leq y_{1} \leq 1$, $0 \leq y_{2} \leq 1,0 \leq y_{3} \leq 1$.

Solver in Microsoft Excel is an efficient tool to solve both equality and inequality constrained non-linear optimization problem [18]. An Excel worksheet for optimization is prepared as shown in 
Figure A1. The objective function is set to target cell for maximization by changing the independent variables (refer to Figure A2). Initial value for feed flow rate, temperature and pressure were set as $1500 \mathrm{~kg} / \mathrm{h}, 150{ }^{\circ} \mathrm{C}$ and $0.00055 \mathrm{kPa}$, respectively. The solution method used for this work is evolutionary; it is for solving a non-smooth non-linear equation. The optimum results of $x_{1}, x_{2}$ and $x_{3}$ were found to be $1291 \mathrm{~kg} / \mathrm{h}, 147^{\circ} \mathrm{C}$ and $0.0007 \mathrm{kPa}$, respectively, and the corresponding responses of $y_{1}, y_{2}$ and $y_{3}$ were $0.000575,0.000937$ and 0.999840 , respectively.

Lastly, model validation is performed to ensure that data inserted into simulation satisfied the prediction. ASPEN HYSYS is simulated using the optimum operating conditions. The responses are shown in Table 11 and regression statistic of model and simulation is shown in Table 12. Clearly, the model equations developed from RSM can be used for predicting responses of the deodorization process.

Table 11. Predicted result from the Response Surface Methodology (RSM) model and ASPEN HYSYS Simulation.

\begin{tabular}{ccc}
\hline Components & $\begin{array}{c}\text { Responses Result from } \\
\text { RSM Model }\end{array}$ & $\begin{array}{c}\text { Responses Result from ASPEN } \\
\text { HYSYS Simulation }\end{array}$ \\
\hline Beta-carotene & 0.000554 & 0.000545 \\
Tocopherol & 0.000896 & 0.000890 \\
FFA & 0.999000 & 0.953000 \\
\hline
\end{tabular}

Table 12. The regression statistics of model and simulation.

\begin{tabular}{cc}
\hline Parameters & Regression Statistics \\
\hline Multiple $R$ & 1 \\
$R$ Square & 1 \\
Adjusted $R$ Square & 1 \\
Standard Error & $3.18 \times 10^{-6}$ \\
Observations & 3 \\
\hline
\end{tabular}

\section{Conclusions}

Simulation and optimization of the refined palm oil process has been considered in this work. A single flash vessel model is developed in ASPEN HYSYS to represent Molecular Distillation (MD) of the refined palm oil process, which has been validated with experimental results from the literature with prediction efficiency errors of less than $3 \%$. Response surface methodology with central composite design was then applied to design of experiments with the validated ASPEN HYSYS model to investigate the effects of feed flow rate, temperature and pressure on concentration of beta-carotene, tocopherol and free fatty acid (FFA) in the MD. The results show that response surface curves of beta-carotene, tocopherol and FFA displayed a similar relationship with respect to temperature and pressure. The result suggested that temperature and pressure and their interaction significantly influences the responses of beta-carotene, tocopherol and FFA, while feed flow rate and their interaction less significantly affected by the responses of beta-carotene, tocopherol and FFA. Finally, the process optimization through Excel solver was carried out using RSM equations, and the optimum operating parameters of MD for refined palm oil process were obtained. These parameters are feasibly suitable for refined palm oil in industrial manufacturing.

Acknowledgments: The authors would like to acknowledge the Prince of Songkla University, Songkhla, Thailand for providing financial support (Grant code: PSU2554-022) for research work.

Author Contributions: This research was carried out in collaboration of all authors. Noree Tehlah performed the simulation and wrote the manuscript. Pornsiri Kaewpradit and Iqbal M. Mujtaba supervised statistical analysis, analysed results, oversaw and approved the final manuscript.

Conflicts of Interest: The authors declare no conflict of interest. 


\section{Appendix}

Table A1. Physical properties of pure components in palm oil, reproduced with permission from [13]. Copyright Springer, 2003.

\begin{tabular}{cccccc}
\hline Component & $\boldsymbol{T}_{\mathbf{B}}(\mathbf{K})$ & $\boldsymbol{T}_{\mathbf{C}}(\mathbf{K})$ & $\boldsymbol{P}_{\mathbf{C}} \mathbf{( k P a )}$ & $\omega$ & $\boldsymbol{V}_{\mathbf{1 2 0}}\left(\mathbf{m}^{\mathbf{3}} \mathbf{\mathbf { k m o l }}\right)$ \\
\hline Tripalmitin & 864.21 & 947.10 & 396.82 & 1.6500 & 0.8906 \\
Triolein & 879.92 & 954.10 & 360.15 & 1.8004 & 0.9717 \\
Oleic acid & 646.52 & 813.56 & 1250.2 & 0.8104 & 0.3172 \\
Tocopherol & 794.52 & 936.93 & 838.45 & 1.1946 & 0.4533 \\
Beta-carotene & 908.58 & 1031.1 & 678.41 & 1.6255 & 0.5348 \\
\hline
\end{tabular}

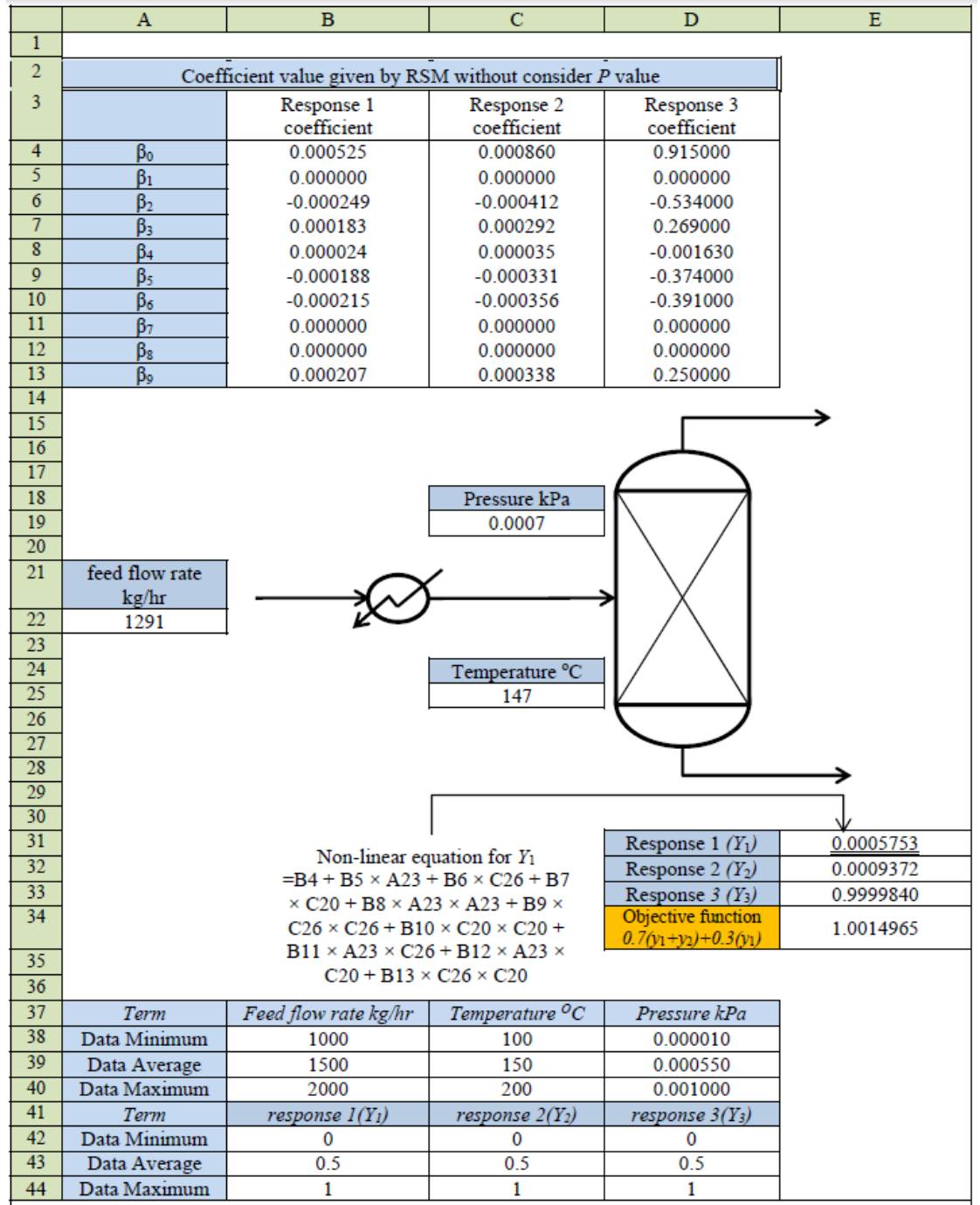

Figure A1. The solver Excel spread sheet. 


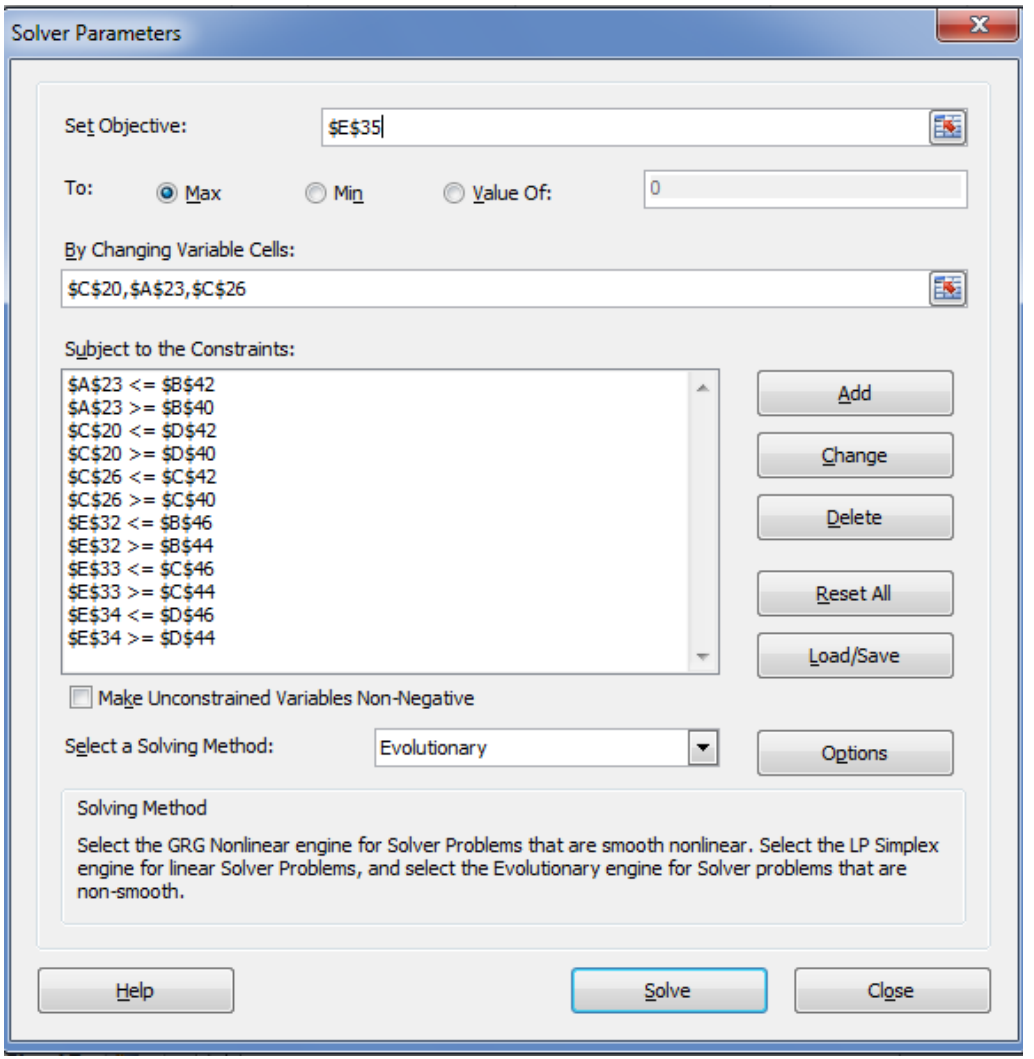

Figure A2. The solver parameters.

\section{References}

1. Nagendran, B.; Unnithan, U.R.; Choo, Y.M.; Sundram, K. Characteristics of red palm oil, a carotene and vitamin E rich refined oil for food uses. Food Nutr. Bull. 2000, 21, 189-194. [CrossRef]

2. Rohani, O.; Sharifah, S.A.; MohdRafii, Y.; Ong, M.; Tarmizi, A.H.; Zamzuri, I. Advances in oil palm Research. Adv. oil palm res. 2000, 1, 238-331.

3. Batistella, C.B.; Maciel, M.R.W. Recovery of caroteniods from palm oil by molecular distillation. Comput. Chem. Eng. 1998, 22, 53-60. [CrossRef]

4. Huang, H.-J.; Ramaswamy, S.; Tschirner, U.W.; Ramarao, B.V. A review of separation technologies in current and future bio refineries. Sep. Purif. Technol. 2008, 62, 1-21. [CrossRef]

5. Casilio, D.; Dunford, N.T. Nutritionally Enhanced Edible Oil and Oilseed Processing; AOCS Press: Champaign, IL, USA, 2004; pp. 178-192.

6. Chen, F.; Cai, T.; Zhao, G.; Liao, X.; Guo, L.; Hu, X. Optimization conditions for the purification of crude octacosanol extract from rice bran wax by molecular distillation analyzed using response surface methodology. J. Food Eng. 2004, 70, 47-53. [CrossRef]

7. Jiang, S.T.; Shao, P.; Pan, L.J.; Zhao, Y.Y. Molecular distillation for recovering tocopherol and fatty acid methyl ester from rapeseed oil deodorizer distillate. Biosyst. Eng. 2006, 93, 383-391. [CrossRef]

8. Wu, W.; Wang, C.; Zheng, J. Optimization of deacidification of low calorie cocoa butter by molecular distillation. Food Sci. Technol. 2011, 46, 563-570. [CrossRef]

9. Zhang, G.; Liu, J.; Liu, Y. Concentraton of omega 3 polyunsaturated fatty acid from oil of schizochytrium limacinum by molecular distillation: Optimization of techonological condition. Ind. Eng. Chem. Res. 2013, 52, 3918-3925.

10. Mallmann, E.S.; Costa, C.B.B.; Maciel, M.R.W.; Filho, M.R. Development of a Computational Tool for simulating falling film molecular design. Comput. Aided Chem. Eng. 2009, 26, 743-748.

11. Unnikrishnan, R. Refining of Edible Oil Rich in Natural Carotenes and Vitamin E. United State Patent 6,177,114 B1, 23 January 2001. 
12. Aspen Technology Aspen Plus User Guide. Available online: https://web.ist.utl.pt/ist11038/acad/Aspen/ AspUserGuide10.pdf (accessed on 7 July 2017).

13. Lim, C.S.; Manan, Z.A.; Sarmidi, M.R. Simulation Modeling of the Phase Behavior of Palm Oil-Supercritical Carbon Dioxide. JAOCS 2003, 80, 1147-1156. [CrossRef]

14. Kalil, S.J.; Mauger, F.; Rodrigues, M.I. Response Surface Analysis and Simulation as a Tool for Bioprocess Design and Optimization. Process Biochem. 1999, 35, 539-550.

15. Wang, H.; Cui, X. Response Surface Optimization of the Operating Parameters for a Complex Distillation Column Based on Process Simulation. Energy Procedia 2012, 16, 571-578. [CrossRef]

16. Khuri, A.I.; Siuli, M. Response Surface Methodology; John Wiley \& Sons: New York, NY, USA, 2010.

17. Elhameh, N. Optimal of Gasoline Vacuum Layer Using Response Surface Methodology. Chem. Eng. Technol. 2013, 37, 229-239.

18. Arora, J.S. Chapter 6 Optimum Design with Excel solve. In Introduction to Optimum Design; Elsevier Inc.: Amsterdam, The Netherlands, 2012; pp. 213-273.

(C) 2017 by the authors. Licensee MDPI, Basel, Switzerland. This article is an open access article distributed under the terms and conditions of the Creative Commons Attribution (CC BY) license (http://creativecommons.org/licenses/by/4.0/). 